Editorial

\title{
Tobacco Control in Low- and Middle-Income Countries: Changing the Present to Help the Future
}

\author{
Bethany Hipple Walters, ${ }^{1}$ Ionela Petrea, ${ }^{1}$ and Harry Lando ${ }^{2}$ \\ ${ }^{1}$ Trimbos International, Trimbos Institute, Utrecht, The Netherlands \\ ${ }^{2}$ Division of Epidemiology and Community Health, University of Minnesota, Minneapolis, Minnesota
}

While the global smoking rate has dropped in the past 30 years (from $41.2 \%$ of men in 1980 to $31.1 \%$ in 2012 and from $10.6 \%$ of women in 1980 to $6.2 \%$ in 2012), the number of tobacco smokers has increased due to population growth ( $\mathrm{Ng}$ et al., 2014). This tobacco use and second-hand smoke exposure continue to harm people worldwide. Those harmed are often vulnerable: children, those living in low- and middle-income countries (LMICs), those with existing diseases, etc. As noted by the World Health Organization (WHO), nearly $80 \%$ of those who smoke live in a LMIC (World Health Organization, 2017). Furthermore, it is often those who are more socioeconomically disadvantaged or less educated in LMICs that are exposed to second-hand smoke at home and work (Nazar, Lee, Arora, \& Millett, 2015).

While a recent meta-analysis of tobacco control interventions for LMICs revealed that medications may be effective at increasing cessation and educating pregnant women on smoking harms can be effective in improving quit rates (Munabi-Babigumira, Fretheim, \& Øverland, 2012), it can be difficult to translate tobacco control into routine care. Planning, development and implementation of tobacco control activities in LMIC are difficult; a study of adding tobacco assistance to TB programs in Pakistan and Nepal revealed that adding tobacco control to care was challenging (Dogar, Elsey, Khanal, \& Siddiqi, 2016). Many smokers in LMICs have little access to education, prevention or assistance. As smoking rates have been decreasing in high-income countries (HICs), many LMICs are targeted by the tobacco industry through marketing and political lobbying; this is especially true in sub-
Saharan Africa (Gilmore, Fooks, Drope, Bialous, \& Jackson, 2015).

Tobacco control experts have long been concerned about the increase in tobacco cultivation, use and the influence of the tobacco industry in sub-Saharan Africa (Taha \& Ball, 1980). Of the 48 nations in sub-Saharan Africa, only one (Seychelles) is rated as a HIC (World Bank, 2017). While many effective tobacco control efforts have been taken (World Health Organization, 2015), research on the Framework Convention on Tobacco Control in Africa showed that most African nations lagged behind on regulating tobacco product packaging, on enforcing smoke-free spaces and on tobacco sponsorship (Tumwine, 2011). More must be done to protect the over 1 billion people who live in LMICs in sub-Saharan Africa from the harms of tobacco.

While research on tobacco control has been conducted in the region, far more research is needed; this is difficult in low resourced, understaffed healthcare settings and universities. Though researchers in many LMICs have free or low-cost access to academic journals (World Health Organization, 2014), other resources, such as funding for tobacco control research and interaction with other tobacco control researchers, may be quite scarce. In an effort to connect tobacco control researchers and other experts from HICs with those from LMICs, the World Conference on Tobacco or Health (WCTOH) will be held in Cape Town, South Africa for the first time in the 50-year history of this conference (World Conference on Tobacco or Health, 2018). The conference theme, Uniting the World for a Tobacco-Free Generation, focuses on global and 
generational issues related to tobacco control. The WC$\mathrm{TOH}$ serves as a forum for networking between researchers, policymakers, health educators, advocates and healthcare providers. The WCTOH provides a unique opportunity to support the tobacco control, healthcare and research infrastructures of LMICs in sub-Saharan Africa; reduced conference fees are available for local delegates, students and nurses. The conference is an important step towards advancing and supporting tobacco control research, advocacy and policy in LMICs and will bring needed attention to tobacco harms in sub-Saharan Africa as well as in LMICs globally.

\section{Acknowledgements}

None.

\section{Financial Support}

This research received no specific grant from any funding agency, commercial or not-for-profit sectors.

\section{Conflict of Interest}

The authors have no conflicts of interest to report.

\section{Ethical Standards}

This research does not involve any human or animal experimentation. The research complies with the ethical standards of the relevant national and institutional guides.

\section{References}

Dogar, O., Elsey, H., Khanal, S., \& Siddiqi, K. (2016). Challenges of integrating tobacco cessation interventions in TB programmes: Case studies from Nepal and Pakistan. Journal of Smoking Cessation, 11(2), 108-115.
Gilmore, A. B., Fooks, G., Drope, J., Bialous, S. A., \& Jackson, R. R. (2015). Exposing and addressing tobacco industry conduct in low-income and middle-income countries. The Lancet, 385(9972), 1029-1043.

Munabi-Babigumira, S. K., Fretheim, A., \& Øverland, S. N. (2012). Interventions for tobacco control in low-and middleincome countries: Evidence from randomised and quasirandomised studies. Report No. 03-2012. Oslo: Norwegian Knowledge Centre for the Health Services.

Nazar, G. P., Lee, J. T., Arora, M., \& Millett, C. (2015). Socioeconomic inequalities in secondhand smoke exposure at home and at work in 15 low- and middle-income countries. Nicotine \& Tobacco Research, 18(5), 1230-1239.

Ng, M., Freeman, M. K., Fleming, T. D., Robinson, M., DwyerLindgren, L., Thomson, B. et al. (2014). Smoking prevalence and cigarette consumption in 187 countries, 19802012. Journal of the American Medical Association, 311(2), 183-192.

Taha, A., \& Ball, K. (1980). Smoking and Africa: The coming epidemic. British Medical Journal, 280(6219), 991-993.

Tumwine, J. (2011). Implementation of the framework convention on tobacco control in Africa: Current status of legislation. International Journal of Environmental Research and Public Health, 8(11), 4312-4331.

World Bank (2007). Retrieved from https://datahelpdesk. worldbank.org/knowledgebase/articles/906519-worldbank-country-and-lending-groups

World Conference on Tobacco or Health (2018). Retrieved from http://wctoh.org/

World Health Organization (2014). HINARI access to research in health programme. Geneva: World Health Organization.

World Health Organization (2015). The WHO framework convention on tobacco control: 10 years of implementation in the African region. World Health Organization.

World Health Organization (2017). WHO tobacco fact sheet. Retrieved from http://www.who.int/mediacentre/factsheets/ fs339/en/ 